\title{
MEDIA MASSA DALAM DIPLOMASI INTERNASIONAL (KEBIJAKAN REDAKSI SURAT KABAR BERBAHASA INGGRIS JP DALAM MEMBERITAKAN HUBUNGAN INDONESIA - SINGAPURA)
}

\author{
Muhammad Gafar Yoedtadi ${ }^{1}$ \\ ${ }^{1}$ Fakultas Ilmu Komunikasi, Universitas Tarumanagara Jakarta \\ Email: gafary@fikom.untar.ac.id
}

\begin{abstract}
ABSTRAK
Hubungan Indonesia - Singapura telah memasuki usia 50 tahun. Hubungan kedua negara tersebut telah terbina dengan baik, namun masih terdapat beberapa masalah. Persoalan kedua negara yang masih menjadi isu sensitif itu, sering kali memancing sentimen negatif masyarakat Indonesia akibat pemberitaan media massa. Sentimen negatif berupa opini publik dapat mendorong kepada keretakan hubungan kedua negara. Mengacu pada teori multi-track diplomacy, peran media massa cukup berpengaruh dalam menjaga harmonisasi hubungan antar negara. Masyarakat umumnya mendapatkan gambaran positif atau negatif mengenai negara tetangga dari pemberitaan media massa. Dalam komunikasi politik internasional, media massa sangat efektif menjadi mediator antar negara. Dalam menanggapi isu tertentu, media massa dapat digunakan sebagai alat diplomasi antar negara. Salah satu media massa yang dinilai penting oleh pemerintah Indonesia dan Singapura adalah surat kabar berbahasa Inggris JP. Penelitian ini berupaya mengetahui kebijakan redaksi surat kabar berbahasa Inggris $J P$ dalam memberitakan hubungan Indonesia - Singapura. Penelitian ini menggunakan perspektif kualitatif bersifat deskriptif dengan metode studi kasus. Pengumpulan data dilakukan dengan wawancara mendalam, observasi dan dokumentasi. Hasil penelitian menunjukkan redaksi JP menjalankan peran diplomasi dalam pemberitaan hubungan Indonesia dan Singapura. Menggunakan teori hirarki pengaruh terhadap media, terlihat kebijakan redaksi JP dalam memberitakan hubungan Indonesia dan Singapura terpengaruh oleh sikap pendirinya Jusuf Wanandi untuk menjaga hubungan baik antar negara ASEAN, dan ideologi JP yang menjunjung nilai-nilai kemanusiaan, perdamaian, demokrasi dan pluralisme.
\end{abstract}

Kata kunci: indonesia, singapura, multi-track diplomacy, hirarki pengaruh media

\section{PENDAHULUAN}

Hubungan Indonesia - Singapura telah memasuki usia 50 tahun pada September 2017 lalu. Hubungan kedua negara terus mengalami kemajuan dan menorehkan banyak prestasi, namun tidak dapat disangkal jika masih terdapat beberapa masalah. Antara lain, persoalan aset-aset sejumlah konglomerat Indonesia yang disimpan di Singapura dalam rangka menghindari pajak pemerintah Indonesia, belum adanya perjanjian ekstradisi antara Indonesia dan Singapura yang menyebabkan negara itu menjadi tempat pelarian favorit sejumlah pelaku kejahatan dari Indonesia, serta kontrol wilayah udara di Riau dan Natuna yang masih dikendalikan oleh Singapura (Liputan 6. Com, 2017).

Persoalan yang masih menjadi isu sensitif itu, sering kali memancing sentimen negatif masyarakat Indonesia akibat pemberitaan media massa. Sentimen negatif berupa opini publik tentu tak mudah diredakan, karena sering kali menyangkut perasaan nasionalisme. Masyarakat umumnya mendapatkan gambaran negatif mengenai negara tetangga dari pemberitaaan media massa (Djelantik, 2015). Pembentukan opini publik dapat dilakukan ketika media massa memberikan perhatian khusus pada satu isu internasional (Baum, 2008). Peran media massa nasional harus diakui cukup berpengaruh dalam menjaga harmonisasi hubungan Indonesia dan Singapura. Media massa sangat efektif menjadi mediator antar negara dalam menanggapi isu tertentu (Thune, 2009). Bahkan media massa dapat digunakan sebagai alat diplomasi antar negara ketika melakukan pembahasan atau perundingan suatu isu internasiona (Stengel, 2017). Bukan rahasia lagi jika pemeritah menggunakan media massa untuk melibatkan opini publik dalam pembentukkan kebijakan luar negeri (Coban, 2016). Dalam hubungan internasional, 
peran media massa nasional pada umumnya akan membawa kepentingan nasional (Saleem, 2007).

Peran media massa dalam diplomasi antar negara dapat disebutkan sebagai peran diplomasi jalur kedua. Diplomasi yang dilakukan pemerintah adalah diplomasi jalur pertama. Diplomasi jalur kedua dilakukan oleh aktor-aktor non-pemerintah atau individu yang bersifat informal (Diamond \& McDonald, 1996). Diplomasi jalur kedua melengkapi upaya-upaya yang dilakukan antar pemerintah. Diplomasi ini dikenal sebagai diplomasi publik dengan memanfaatkan banyak jalur di luar pemerintah atau disebut multi-track diplomacy (Djelantik, 2008). Jalur diplomasi tersebut adalah: pertama, pemerintah; kedua, para profesional nonpemerintah; ketiga, bisnis atau hubungan dagang; keempat, warga negara sipil; kelima, penelitian atau pelatihan dan edukasi; keenam, aktivisme dalam perdamaian, HAM, lingkungan, keadilan sosial; ketujuh, agama bertujuan pada perdamaian; kedelapan, pendanaan (funding) bertujuan pada perdamaian; kesembilan, komunikasi dan media massa bertujuan perdamaian melalui informasi (Diamond \& McDonald, 1996).

Sebagai negara tetangga yang minim sumber daya, pemerintah Singapura sangat menjaga hubungan baik dengan pemerintah dan rakyat Indonesia. Riak dan gejolak yang terjadi akibat pemberitaan media massa akan ditanggapi serius oleh pemerintah Singapura. Pemerintah Singapura menyadari peran media massa Indonesia sebagai mediator dalam hubungan dua negara. Lewat media massa Indonesia, pemerintah Singapura berharap dapat membentuk citra positif pada masyarakat Indonesia. Karena itu pada peringatan hubungan Indonesia dan Singapura ke 50 tahun pada 2017 lalu, pemerintah Singapura mengundang sejumlah wartawan dari media massa Indonesia untuk berkunjung ke Singapura. Dalam program bertajuk "Indonesian Journalist Visit Program 2017" (IJVP), para wartawan dipertemukan dan berdiskusi dengan sejumlah elit pemerintahan Singapura. Pemerintah Singapura berharap, program tersebut dapat memberikan perspektif lebih objektif atas isu-isu kedua negara di mata media masa Indonesia. Salah satu media massa nasional yang diundang dalam program IJVP 2017 adalah surat kabar berbahasa Inggris JP. Penelitian ini ingin mengungkap kebijakan redaksi berbahasa Inggris JP dalam memberitakan hubungan Indonesia dan Singapura.

\section{METODE PENELITIAN}

Penelitian ini menggunakan perspektif kualitatif bersifat deskriptif dengan metode studi kasus. Peneliti menggunakan wawancara mendalam, observasi, dan dokumentasi untuk mengumpulkan data. Narasumber yang dipilih untuk mengetahui kebijakan redaksi surat kabar berbahasa Inggris JP adalah seorang anggota redaksi setingkat redaktur yang akan bertindak sebagai informan. Agar lebih bebas dalam memberikan informasi, nama informan dirahasiakan. Surat kabar berbahasa Inggris JP dipilih sebagai objek penelitian karena termasuk media massa yang diundang oleh pemerintah Singapura untuk mengikuti "Indonesian Journalist Visit Program" (IJVP) pada peringatan 50 tahun hubungan RI dan Singapura yang diselenggarakan September 2017. Peneliti juga mewawancarai seorang diplomat Singapura yang bertugas di Indonesia untuk mengetahui pandangan pemerintah Singapura terhadap peran diplomasi yang dijalankan media massa Indonesia. Untuk medapatkan informasi secara lebih mendalam nama diplomat Singapura tidak akan diungkapkan dalam laporan penelitian.

\section{HASIL DAN PEMBAHASAN}

Menurut redaksi surat kabar berbahasa Inggris JP, perhatian JP terhadap berita luar negeri cukup besar, karena setiap hari pada halaman utamanya selalu terdapat tiga berita headline, 
yakni berita nasional, berita bisnis dan berita politik luar negeri. Komposisi ini berlaku setiap edisi sepanjang tidak ada peristiwa yang sangat besar (insidental) untuk dijadikan headline utama, misalnya, terjadi bencana letusan gunung.

Redaksi JP mengakui memiliki perhatian khusus terhadap peristiwa dan isu luar negeri, terutama negara-negara yang tergabung dalam ASEAN. JP secara kontinu memberi perhatian terhadap dinamika hubungan kerja sama negara-negara ASEAN. Perhatian khusus terhadap negara-negara ASEAN dapat terlihat dari halaman khusus untuk berita-berita negara ASEAN pada halaman internasional. Demikian halnya pada halaman bisnis, terdapat juga halaman khusus berisi berita-berita bisnis ASEAN.

Kebijakan redaksi untuk memperhatikan negara-negara ASEAN didasari pada sikap salah satu pendiri sekaligus salah satu pemilik dari JP, yakni Jusuf Wanandi. Jusuf Wanandi memberikan perhatian terhadap kerja sama antar negara ASEAN dan persoalan politik luar negeri lewat lembaganya Center for Strategic and International Studies (CSIS). Sehingga JP ikut memberi perhatian lebih terhadap hubungan bilateral negara-negara ASEAN, termasuk isu hubungan kerja sama Indonesia dan Singapura. Kebijakan redaksi itu terlihat pula dari keikutsertaan JP sebagai anggota ASIA News Network, yakni kerja sama media-media dari negara-negara wilayah Asia. Sebagaimana dijelaskan redaktur JP:

"JP ini fokus kepada kerja sama luar negeri khususnya ASEAN, karena salah satu pendirinya, Jusuf Wanandi, pendiri CSIS, fokus kepada diplomasi studi internasional dan dia juga anggota penasehat ASEAN, jadi mau tak mau JP mempunyai fokus yang tinggi terhadap kerja sama ASEAN, jadi kerja sama Indonesia - Singapura memang harus diperhatikan."

Merujuk pada teori hirarki pengaruh terhadap media (hierarchy of influence) dari Pamela dan Reese, dalam produksi berita media massa akan terpengaruh oleh berbagai faktor internal dan eksternal. Terdapat lima pengaruh terhadap media massa ketika memproduksi berita, antara lain (1) pengaruh individual atau pekerja media (2) pengaruh rutinitas media (3) pengaruh organisasional (4) pengaruh dari luar organisasi (5) pengaruh ideologi (Perloff, 2014). Kebijakan redaksi JP yang terpengaruh oleh salah seorang pemiliknya (Jusuf Wanandi) adalah pengaruh dari salah satu faktor dalam hirarki pengaruh yaitu pengaruh organisasional. Pengaruh organisasional merupakan

Dari hasil wawancara terungkap bahwa redaksi JP mejalankan peran diplomasi internasional. JP memiliki visi dan misi mendukung dan mengembangkan kemanusiaan, perdamaian, demokrasi dan pluralisme. Dalam diplomasi hubungan antar negara, JP lewat berita-beritanya ingin memastikan bahwa nilai-nilai kemanusiaan, perdamaian, demokrasi dan pluralisme dapat terselenggara. Dalam hal menyoroti hubungan bilateral Indonesia - Singapura, misalnya, JP berkeinginan agar hubungan kedua negara dapat berlangsung secara damai dan dapat memberi kesejahteraan terhadap masyarakat di kedua negara. Bagi JP, hubungan Indonesia dan Singapura menjadi prioritas perhatian redaksi, karena Singapura merupakan tetangga terdekat Indonesia dan hubungan keduanya harus berlangsung secara positif.

Mengacu pada teori hirarki pengaruh terhadap media (hierarchy of influence) dari Shoemaker dan Reese (Perloff, 2014) maka visi dan misi JP yang mendukung prinsip kemanusiaan, perdamaian, demokrasi dan pluralisme yang tersirat dalam setiap pemberitaan itu dapat dikategorikan sebagai pengaruh kelima dalam hirarki pengaruh yaitu pengaruh ideologi. Pengaruh ideologi merupakan sebuah pengaruh paling menyeluruh dari semua pengaruh. 
Ideologi di sini diartikan sebagai mekanisme simbolik yang menyediakan kekuatan-kekuatan kohesif yang mempersatukan di dalam masyarakat. (Sobur, 2009). Ideologi diartikan sebagai kerangka berpikir atau referensi tertentu yang dipakai individu untuk melihat realitas dan bagaimana mereka menghadapinya. Ideologi di sini tidaklah selalu harus dikaitkan dengan ideide besar. ideologi juga bisa bermakna politik penandaan atau pemaknaan. Cara wartawan melihat peristiwa dengan kacamata dan pandangan tertentu, dalam arti luas adalah sebuah ideologi (Eriyanto, 2002).

Beberapa contoh permasalahan antara Indonesia dan Singapura, JP akan mengambil sudut pandang (angle) yang sesuai dengan visi misinya. Dalam memberitakan persoalan hubungan Indonesia dan Singapura, JP mengambil sudut pandang bahwa persoalan kedua negara tersebut harus dapat diselesaikan secara damai sepanjang memiliki niat untuk saling membantu dalam upaya penyelesaian. Berikut penjelasan redaktur JP:

"Jadi pada hubungan pemerintah Indonesia dengan pemerintah Singapura, kita melihat bagaimana agar hubungan antara kedua negara tersebut bisa berdiplomasi secara damai, kemudian bagaimana hubungan kedua negara itu bisa meningkatkan kesejahteraan masyarakat kedua negara itu, JP harus menyuarakan hal itu."

Pada kasus kebakaran hutan yang menimbulkan bencana asap, misalnya, sudut pandang JP tidak hanya menyoroti kelemahan penanganan kebakaran hutan oleh Indonesia, tapi juga mempersoalkan beberapa perusahaan perkebunan milik pengusaha Singapura di Sumatera yang ikut membakar hutan. Perspektif yang hendak dihadirkan oleh JP adalah persoalan asap akibat kebakaran hutan di Indonesia, bukan hanya persoalan Indonesia, tapi juga tanggung jawab bersama dengan Singapura.

"Posisi JP adalah mempertanyakan apa yang terjadi, kenapa praktik pembukaan lahan dengan pembakaran hutan masih terjadi, tapi kami juga mengkritisi perusahaan siapa yang membakar hutan itu, perusahaan Singapura kenapa diam saja."

Demikian halnya dengan pemberitaan pada kasus aset-aset orang kaya Indonesia yang banyak disimpan di Singapura. Sudut pandang yang diambil JP adalah mendorong pemerintahan kedua negara agar bersedia menjalin kerjasama dalam mempertukarkan informasi keuangan. Dalam beritanya JP menyuarakan agar Singapura bersedia untuk memberikan informasi data aset warga negara Indonesia yang disimpan di negara itu. Sementara JP juga mendorong pemerintah Indonesia untuk terus berupaya menawarkan kerja sama pertukaran data aset tersebut kepada pemerintah Singapura.

"Kami juga menyuarakan agar pemerintah Singapura bisa bekerja sama agar pemerintah kita bisa melacak aset-aset tersebut. Kita mendorong supaya pemerintah terus melanjutkan kerja sama, pertukaran informasi, keterbukaan datadata, posisi kita memberitakan supaya Singapura mau bekerja sama dan pemerintah kita melanjutkan."

Sementara pada pemberitaan kasus pengendalian ruang udara di Riau - Natuna yang masih dipegang oleh Singapura, JP mengambil sudut pandang bahwa penting bagi Indonesia untuk mengambil alih kendali ruang udara di Riau - Natuna tersebut karena hal itu menyangkut persoalan kedaulatan negara. Namun JP juga memaparkan persoalan yang sesungguhnya dalam beritanya, bahwa kendali ruang udara bisa berada di tangan Singapura disebabkan oleh 
ketidakmampuan Indonesia, terutama dari sisi infrastruktur, untuk memegang kontrol ruang udara tersebut. Persyaratan yang ditentukan oleh Organisasi Penerbangan Sipil Internasional (ICAO) belum mampu dipenuhi oleh Indonesia.

“Ternyata itu juga karena ketidakmampuan kita, satu sisi kita menyayangkan kenapa pemerintah kita di wilayah kita tidak memiliki kontrol terhadap wilayah udara kita, tetapi sisi lain ada faktor kita tidak memiliki kemampuan dan teknologi."

Redaksi JP mengakui menjalankan peran diplomasi untuk mempengaruhi politik internasional. Dengan menjalankan peran diplomasi tersebut, JP ingin ikut membantu menyelesaikan persoalan dunia internasional. Hal ini sesuai dengan teori multy-track diplomacy, bahwa peran diplomasi dapat dijalankan pada dua jalur, jalur pertama adalah pemerintah, jalur kedua dijalankan oleh aktor-aktor non-pemerintah. Media massa dapat mempengaruhi kebijakan luar negeri sebuah negara. Peran tersebut dapat dilakukan media massa dengan memberikan perhatian khusus dan mengekspos berita yang cukup besar pada suatu kasus internasional. Dengan cara itu akan mendorong perhatian publik internasional yang besar pada kasus tersebut, pada akhirnya dapat memaksa dunia internasional menyelesaikan persoalan.

\begin{abstract}
"Saya setuju jika dikatakan JP ikut berdiplomasi untuk menyelesaikan persoalan internasional, misalnya pada krisis di Myamar, dimana warga Rohingya yang terusir dari wilayahnya, pada awalnya pemerintah Myamar seperti mengabaikan suara internasional, bahkan Aung San Suu Kyi seperti menutup telinga, namun setelah media berulang kali menyoroti hal tersebut, mendorong diplomasi dan loby berbagai negara, pemerintah Myanmar mulai memperhatikan. Isu yang sangat besar dan kemudian dimuat secara besar oleh media bisa mendorong pemerintah untuk bertindak."
\end{abstract}

Redaksi JP mengakui, bahwa pandangan redaksi dalam menyoroti kasus hubungan Indonesia dan Singapura, selalu mengedepankan kepentingan bangsa Indonesia. Namun, dengan catatan, bahwa kepentingan bangsa tidak bertentangan dengan prinsip-prinsip universal yang dianut JP dalam visi misinya, yaitu kemanusiaan, perdamaian, demokrasi dan pluralisme. Hal itu akan terlihat dalam opini redaksi yang tertuang dalam editorial JP.

\title{
4. KESIMPULAN DAN SARAN
}

\section{Kesimpulan}

Redaksi surat kabar berbahasa Inggris JP mengakui bahwa selama ini telah menjalankan peran diplomasi dalam pemberitaan hubungan Indonesia dan Singapura, dan politik internasional. Redaksi surat kabar berbahasa Inggris JP meyakini peran media massa sangat penting dalam mempengaruhi kebijakan politik luar negeri antar negara, dan dapat ikut berperan serta dalam menyelesaikan persoalan politik internasional.

Surat kabar berbahasa Inggris JP menjalankan peran diplomasi internasional, karena memiliki keinginan agar hubungan Indonesia dan Singapura dapat terjalin dengan baik, damai dan memberikan kesejahteraan bagi masyarakat di kedua negara tersebut. Keinginan tersebut sejalan dengan visi dan misi JP yaitu mempromosikan nilai kemanusiaan, perdamaian, demokrasi dan pluralisme. 
Redaksi JP menempatkan hubungan Indonesia dan Singapura sebagai fokus perhatian yang sangat penting. Kebijakan redaksi tersebut secara tak langsung terpengaruh oleh sikap salah seorang pendiri dan pemilik JP, Jusuf Wanandi, yang juga memberikan perhatian besar terhadap hubungan antar negara ASEAN dan politik internasional lewat lembaganya CSIS. Fokus perhatian terhadap peristiwa dan isu negara ASEAN terlihat dari halaman khusus berita ASEAN yang disediakan oleh JP.

Dalam memberitakan hubungan Indonesia dan Singapura redaksi surat kabar berbahasa Inggris JP selalu mengedepankan kepentingan bangsa. Sepanjang kepentingan bangsa tersebut tidak bertolak belakang dengan prinsip kemanusiaan, perdamaian, demokrasi dan pluralisme.

\section{Saran}

Penulis menyarankan untuk melakukan penelitian lebih lanjut mengenai pengaruh media sosial terhadap kebijakan luar negeri antar negara. Surat kabar JP merupakan media konvensional, pengaruhnya diduga telah berkurang semenjak adanya media sosial. Komunikasi politik luar negeri saat ini diduga lebih banyak dipengaruhi oleh media sosial.

\section{Ucapan Terima Kasih (Acknowledgement)}

Terima kasih kepada redaksi surat kabar berbahasa Inggris JP yang telah memberi kesempatan peneliti untuk melakukan penelitian. Terima kasih kepada Direktorat Penelitian dan Pengabdian kepada Masyarakat Universitas Tarumanagara, dalam mendukung dana penelitian.

\section{REFERENSI}

Barston, R.P. (2008). Modern diplomacy. New York: Longman.

Baum, M. A, \&, Potter, P. B. K. (2008). The relationships between mass media, public opinion, and foreign policy: toward a theoretical synthesis. The Annual Review of Political Science. University of California.

Coban, F. (2016). The Role of the media in international relations: From the CNN Effect to the $\mathrm{Al}$-Jazeere Effect. Journal of International Relations and Foreign Policy. 4(2). 45-61

Diamond, L., \& McDonald, J. (1996). Multi-track diplomacy: A system approach to peace 3rd ed. New York: Kumarian Press.

Djelantik. S. (2008). Diplomasi antara teori dan praktik. Yogyakarta: Graha Ilmu.

Djelantik, S., Indraswari, R., Triwibowo, A., Apresian, S.R. (2015). Komunikasi internasional dalam era informasi dan perubahan sosial di indonesia. Bandung: Lembaga Penelitian dan Pengabdian Kepada Masyarakat Universitas Katolik Parahyangan.

Kementerian Luar Negeri Republik Indonesia. (2015). Diplomasi indonesia 2014. Jakarta: Direktorat Informasi dan Media Kemlu RI.

Kriyantono, R. (2007). Teknik praktis riset komunikasi. Jakarta: Kencana Prenada Media Group.

Louw, E P. (2005). The media and political process. Londong: Sage.

Perloff, R. M. (2014). The dinamics of the political communication: Media and Politic in the Digital Age. New York: Routledge. 
Power, S. (2013). Media, diplomacy, geopolitics. In Andrew F. Cooper, Jorge Heine, Ramesh Takur (Eds) The Oxford Handbook of Modern Diplomacy. Oxford: Oxford University Press.

Rahardjo, M. (2017). Studi kasus dalam penelitian kualitatif: Konsep dan Prosedur. Malang: Program Pasca Sarjana Universitas Islam Negeri Maulana Malik Ibrahim.

Saleem, Noshina. (2007). U.S. Media Framing of Foreign Countries Image: An Analytical Perspective. Canadian Journal of Media Studies, 2(1). 130-162.

Soroka, Stuart N. (2003). Media, public opinion, and foreign Policy. The International of Press/Politics, 8(1). 27-48.

Stengel, F.A., \& Baumann, R. (2017). Non-State Actors and Foreign Policy. Oxford Research Encyclopedia of Foreign Policy Analysis. Oxford: Oxford University Press.

Sugiyono. (2011). Metode Penelitian Kuantitatif, Kualitatif, dan R\&D. Bandung: CV Alfabeta.

Thune, H. (2009). Beyond the CNN Effect: Towards a Constitutive Understanding of Media Power in International Politics. (PhD Dissertation). University of Oslo, Oslo.

Yin, R. K. (2013). Studi kasus: Desain \& metode. jakarta: PT Rajagrafindo Persada. Jakarta. 